\title{
RESEARCH
}

Open Access

\section{Geographic differences in maternal and child health care utilization in four Ethiopian regions; a cross-sectional study}

\author{
Atkure Defar ${ }^{1,2^{*}}$ (D), Yemisrach B. Okwaraji ${ }^{1,3}$, Zemene Tigabu ${ }^{4}$, Lars Åke Persson ${ }^{1,3}$ and Kassahun Alemu ${ }^{2}$
}

\begin{abstract}
Background: Maternal and child health $(\mathrm{MCH})$ care utilization often vary with geographic location. We analyzed the geographic distribution and determinants of utilization of four or more antenatal care visits, health facility delivery, child immunization, and care utilization for common childhood illnesses across four Ethiopian regions.

Methods: A cross-sectional community-based study was employed with two-staged stratified cluster sampling in 46 districts of Ethiopia. A total of 6321 women (13-49years) and 3110 children below the age of 5 years residing in 5714 households were included. We performed a cluster analysis of the selected MCH care utilization using spatial autocorrelation. We identified district-specific relationships between care coverage and selected factors using geocoded district-level data and ordinary least squares and hotspot analysis using Getis Ord Gi*

Results: Of the 6321 women included in the study, 714 had a live birth in the 12 months before the survey. Onethird of the women $(30,95 \% \mathrm{Cl} 26-34)$ had made four or more antenatal visits and almost half of the women (47, 95\% $\mathrm{Cl} 43-51)$ had delivered their most recent child at a health facility. Nearly half of the children $(48,95 \% \mathrm{Cl} 40-$ 57) with common childhood illnesses (suspected pneumonia, diarrhoea, or fever) sought care at the health facilities. The proportion of fully immunized children was $41 \%(95 \%, \mathrm{Cl} 37-45)$. Institutional delivery was clustered at district level (spatial autocorrelation, Moron's $I=0.217, P<0.01$ ). Full immunization coverage was also spatially clustered (Moron's I $=0.156, P$-value $<0.1$ ). Four or more antenatal visits were associated with women's age and parity, while the clustering of institutional delivery was associated with the number of antenatal care visits. Clustering of full immunization was associated with household members owning a mobile phone.

Conclusions: This study showed evidence for geographic clustering in coverage of health facility deliveries and immunization at the district level, but not in the utilization of antenatal care and utilization of health services for common childhood illnesses. Identifying and improving district-level factors that influenced these outcomes may inform efforts to achieve geographical equitability and universal health coverage.
\end{abstract}

Keywords: Ethiopia, Utilization, Antenatal care, Immunization, Childhood illness, Spatial analysis, Autocorrelation, Geographical variation, Ordinary Least Square, Getis Ord Gi*

\footnotetext{
* Correspondence: atkuredefar@gmail.com

${ }^{1}$ Ethiopian Public Health Institute, Addis Ababa, Ethiopia

2Department of Epidemiology and Biostatistics, Institute of Public Health,

College of Medicine and Health Sciences, University of Gondar, Gondar,

Ethiopia

Full list of author information is available at the end of the article
}

(c) The Author(s). 2019 Open Access This article is distributed under the terms of the Creative Commons Attribution 4.0 International License (http://creativecommons.org/licenses/by/4.0/), which permits unrestricted use, distribution, and reproduction in any medium, provided you give appropriate credit to the original author(s) and the source, provide a link to the Creative Commons license, and indicate if changes were made. The Creative Commons Public Domain Dedication waiver (http://creativecommons.org/publicdomain/zero/1.0/) applies to the data made available in this article, unless otherwise stated. 


\section{Background}

Improving the utilization of maternal and child health services has been an important way of reducing the risk of maternal and child deaths. In Ethiopia, efforts have been made to improve the utilization of key maternal and child health services, resulting in an increase in the use of these services in the past decades. For instance, from 2005 to 2015, the utilization of four or more antenatal care visits increased from 12 to $32 \%$, and skilled birth attendance increased from 6 to $28 \%$ [1].

Despite these overall improvements, there are geographic variations in the utilization of these services [2,3]. A further analysis of the Ethiopian 2016 Demographic and Health Survey (DHS) revealed a geographic variation in postnatal care coverage (Moran's $\mathrm{I}=0.08$ ) [4]. Similarly, a study conducted to assess the geographical variation of antenatal care utilization showed higher utilisation in urban settings and lower in pastoralists regions [5].

There is also geographic variation in childhood illness and utilization of child health services across Ethiopia as well as across the African continent [2, 6, 7]. A systematic review conducted to assess the geographical variation of care utilization in 27 selected African countries showed variation in immunization coverage and care-seeking at national and subnational levels $[2,8]$. A low coverage of immunization at national and subnational levels was observed to a larger extent in Ethiopia as compared to other countries included in the study. Furthermore, the study reported variation in careseeking for common childhood illness between countries. It was found to be low in Ethiopia (29\%) and high in Uganda (78\%). Clustering of low values was mainly shown in western Africa, Ethiopia, Zimbabwe, and a small section of central Africa [2].

The geographical characteristics of an area with variations in travel time to the nearest health facility are found to be the main explanation to the geographical variation in the utilization of maternal and child health services [9]. There are some studies that used geographic information system (GIS) modelling to explore factors associated with the geographical clustering of these services $[10,11]$. However, these studies did not explore factors associated with the geographic clustering using advanced spatial methods [12, 13].

There is a range of GIS-based advanced spatial methods that provide appropriate analyses for the assessment of the geographic variation of health care utilization [14-16]. Such methods allow for explicit use of GIS-linked data to study the geographical variation of care utilization [17] and perform in-depth analyses of factors associated with the geographical variation $[18,19]$.
Thus, the aim of this study was to identify the geographic variation of selected maternal and child health services utilization (antenatal care, institutional delivery, child immunizations, and care-seeking for common childhood illness) and the factors associated with the observed spatial variation in four regions of Ethiopia by applying a geographical analysis approach including spatial pattern analysis global (Spatial Autocorrelation) and Ordinary Least Square method (OLS).

\section{Methods}

\section{Study setting and population}

The study was conducted in 46 districts in the four most populous regions of Ethiopia: Tigray, Oromia, Amhara, and the Southern Nations, Nationalities and Peoples (SNNP) (Fig. 1). According to the $2018 \mathrm{UN}$ population estimates, the population size of Ethiopia was 107,099, 196 with $79 \%$ of the population living in rural settings and over $80 \%$ of the country's population residing in these four regions. The topography is dominated by hilly areas.

\section{Study design}

The study was a cross-sectional community-based survey conducted from December 2016 to February 2017 in intervention and comparison districts selected for the implementation of the Optimizing the Health Extension Program (OHEP), which aimed at increasing the utilization of health services for sick newborns and children below the age of 5 years. The comparison districts had similar socio-demographic characteristics as the intervention districts. The survey was performed prior to the implementation of OHEP. The evaluation of this intervention was registered in the Current Controlled Trials ISRCTN12040912.

\section{Sampling}

A two-stage stratified cluster sampling was applied in the selected study districts. The first stage used lists of enumeration areas (EA) from the 2007 Ethiopian Housing and Population Census as the sampling frame [20]. The cumulative population size of enumeration areas across the study areas was calculated, and 200 EAs were selected with probability proportional to size. Each EA formed one cluster, and these clusters constituted the primary sampling unit.

In the second stage, a systematic random sampling technique was used. All households within each cluster were listed and a sampling interval was calculated. A random start number between one and the sampling interval was selected. The households that matched the random start number in the list was thereafter selected as the first household to be included. This process was repeated until the targeted number of 30 households in 

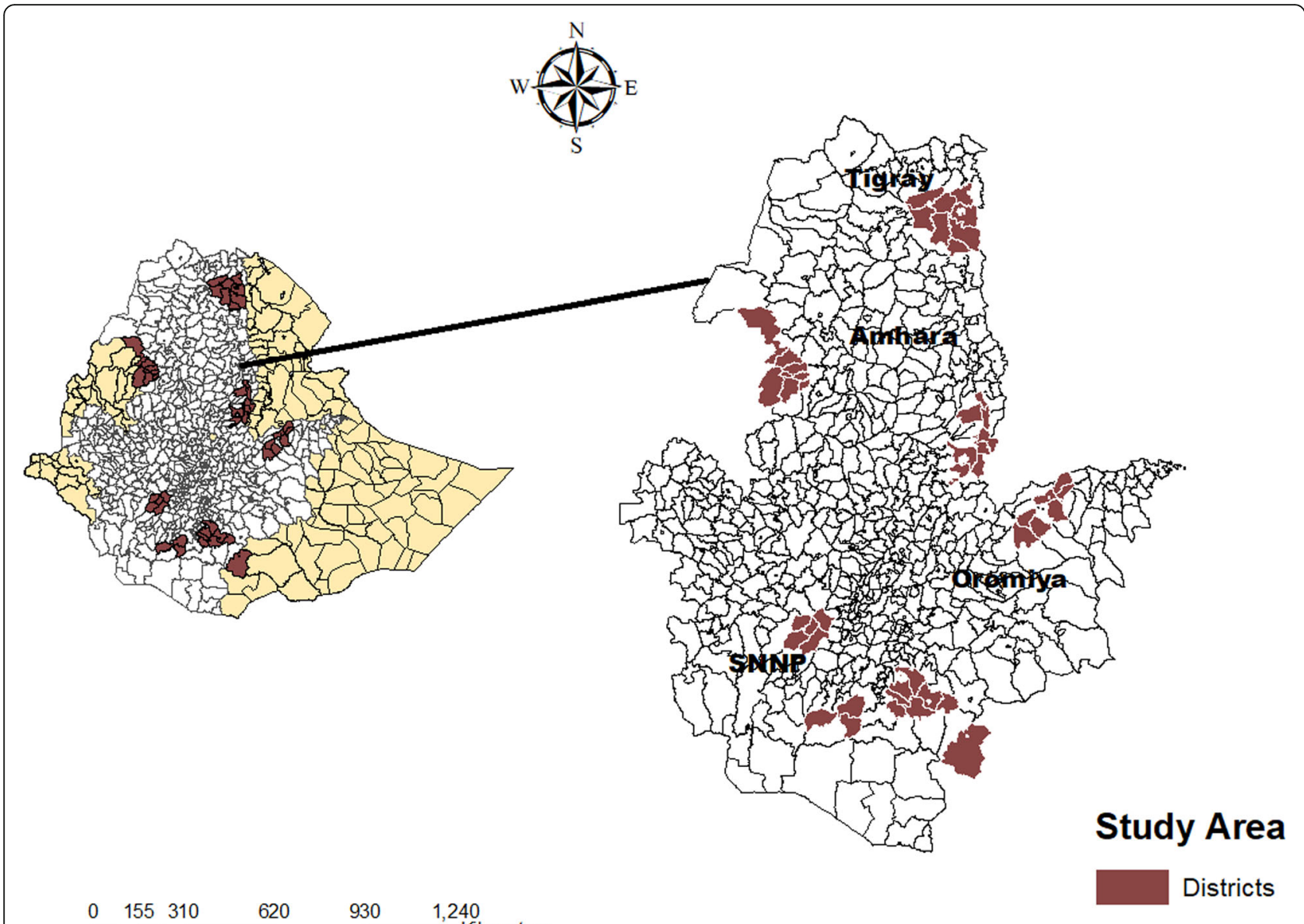

Kilometers

Fig. 1 Map of Ethiopia indicating the regions and districts where the study was undertaken

each cluster was reached. All women aged 13 to 49 years and children under the age of 5 years, who lived in the selected households, were included in the survey.

We used a standard sample size formula with a design effect of 1.3 . We used $80 \%$ power and the assumption of a ratio of 0.65 children less than 5 years of age per household, based on sampling reported in the Ethiopia DHS 2011. Finally, a total sample size of 6000 households was estimated.

\section{Study participants}

Women of reproductive age (13-49 years), who had given birth during the last year, and children aged less than 5 years were the primary subjects of this study. Mothers or caregivers of the included children were interviewed regarding their care-seeking behaviour for themselves and their children.

\section{Survey methods}

There were 15 data collection teams; each team comprised one team leader and three enumerators. Data were collected using tablet computers. Data collectors were trained for 10 days covering study procedures, questionnaires, data collection techniques, quality assurance procedures, and study ethics. A field manual was provided to data collectors and the survey tools were pilot-tested in the field during the last 3 days of the training.

The interviewers first obtained informed consent from the house head and collected information on sociodemographic characteristics of the household and all members of the household. This was followed by interviews of all women of reproductive age (13 to 49 years) to get information on live births in the 12 months preceding the survey including information on utilization of antenatal care and delivery care, and their knowledge of pregnancy and newborn danger signs. Childhood immunization status, children's two-weeks morbidity recalls, and health care utilization for any recent child illness episode were also collected from caregivers or mothers of children between the age of 2-59 months who resided in the household. The questionnaire modules were based on existing large-scale survey tools, such as the Demographic and Health Surveys, the Service 
Provision Assessment, the Averting Maternal Death and Disability, and Safe Motherhood survey tools and had been piloted and adapted for this survey.

\section{Outcome variables}

We estimated the overall coverage of four selected maternal and child health services. For women, this included the utilization of four or more antenatal care visits and institutional delivery. For children 2-59 months with illness during the last 2 weeks, care-seeking to health posts, health centers, hospitals, or private clinics was included. Further, we assessed the proportion of children aged 12-23 months, who were fully immunized in accordance with the national immunization program (Table 1).

\section{Explanatory variables}

Selected environmental, household, and individual factors were included in the analytical models and assessed for their random geographical distribution across the study areas before using in the spatial analysis. Variables considered as household factors were having family health cards, owning mobile, radio, or television set in the household, participation in women's development groups, and the number of pregnancies and births. Variables considered as individual factors were education status of the mother, age of the mother and the child, sex of the child, and the number of health facility visits. Health system-level factors were the availability of health post in the village (kebele) and reported distance to the nearest health post. The altitude of the household was considered an environmental factor.

\section{Spatial variables}

Shapefiles of each district were obtained from the Central Statistical Agency, Ethiopia. These data had the X and Y coordinates and spatial areas of districts, which made up the polygon file for each district in the study areas.

\section{Data analyses}

Measuring outcomes and explanatory variables

Descriptive analysis was done to generate service utilization at the district level for selected outcome indicators. These proportions for the use of maternal and child health services were calculated from the total women aged from 13 to 49 years with live births in the 12 months period prior to the study, children from 2 to 59 months old, and children from 12 to 23 months old.

District level mean values of continuous variables and proportions of categorical variables were also calculated for explanatory variables. All analyses were done using STATA 14 software (StataCorp LLC, Texas, United States).

\section{Spatial variation of maternal and child health care utilization}

A database was created including spatial information, care utilization outcomes, and explanatory variables. The outcome and explanatory variables were linked with spatial data at the district level using ArcGIS Desktop v10.5 (Environmental Systems Research Institute Inc., Redlands CA, USA). The Spatial Autocorrelation matric equation is expressed [21] as;

$$
I(d)=\frac{\frac{1}{W} \sum_{k-1}^{n} \sum_{i-1}^{n} W_{k i}\left(y_{k}-\bar{y}\right)\left(y_{i}-\bar{y}\right)}{\frac{1}{n} \sum_{i-1}^{n}\left(y_{i}-\bar{y}\right)^{2}}
$$

Where: $I(d)=$ Moran's $I$ correlation coefficient as a function of distance. $\mathrm{W}_{k i}=\mathrm{a}$ matrix of weighted values, where elements are a function of distance $1=y_{h}$ and $y_{i}$ are within a given distance class, for $y_{h} y_{i} 0=$ all other cases. The value of $I$ could depend on the assumptions built into the spatial weight's matrix $\mathrm{W}_{\mathrm{ij}}$.

Maternal and child health care utilization data at the district level were assessed for geographical clustering using spatial autocorrelation (Moran's Index). The spatial autocorrelation analysis estimated the Moran's Index and

Table 1 Definition of the studied maternal and child health services utilization

\begin{tabular}{ll}
\hline Health service & Definition \\
\hline $\begin{array}{l}\text { Four or more antenatal care } \\
\text { visits }\end{array}$ & $\begin{array}{l}\text { The proportion of women aged } 13 \text { to } 49 \text { with a live birth in the last } 12 \text { months who attended antenatal care four } \\
\text { or more times during that pregnancy. }\end{array}$ \\
$\begin{array}{l}\text { Institutional delivery } \\
\text { Child immunization; fully }\end{array}$ & $\begin{array}{l}\text { The proportion of women with a live birth in the year preceding the survey who gave birth in a health facility } \\
\text { immunized }\end{array}$ \\
$\begin{array}{ll}\text { three doses of polio vaccine and three doses of pentavalent vaccine (Diphtheria-Tetanus-Pertussis-Hepatitis B and } \\
\text { Childhood illness }\end{array}$ & $\begin{array}{l}\text { The proportion of children aged 2-59 months with fever, diarrhoea, or suspected pneumonia in the last two } \\
\text { weeks for whom care was sought at health posts, health centers, hospitals, or private clinics }\end{array}$ \\
\hline
\end{tabular}


the $\mathrm{z}$ score, and its associated $p$-values were computed for observed and expected index values, given the number of features and the variance of the data values. A positive Moran's Index value indicates a tendency toward clustering while a negative Moran's Index value indicates a tendency toward dispersion. This analytical model hypothesized that the geographical distribution of utilization of the selected maternal and child health services was randomly distributed. The concept implies that nearby locations tend to be more alike than locations that are far away from one another [17]. Thus, the analysis measures spatial autocorrelation based on feature locations and attribute values. It estimates within and across regional and district boundaries using the Moran's I statistic to decide whether the pattern expressed is clustered, dispersed, or random.

\section{Linear regression and hot spot analysis}

The global Ordinary Least Square (OLS) linear regression method was used to predict the relationship between selected explanatory variables and the outcome variables. Spatial autocorrelation in the residuals of the OLS models was thereafter again tested by Moran's I statistics to ascertain that the residual was not clustered. A spatial autocorrelation coefficient, which may range from -1 (negative autocorrelation) to +1 (positive spatial autocorrelation), was used to decide. If we found the existence of the spatial autocorrelation in the residuals, the OLS model would not fit the data set and further refined spatial models should be used. In such a case, a hot spot analysis was done using Getis Ord $\mathrm{Gi}^{*}$, which estimates a z-score of the observed and expected spatial clustering with high or low values and its associated $p$-values. The result of Getis Ord $\mathrm{Gi}^{*}$ tells us how strong the linear model is within and between geographic areas and identifies which areas that contribute to a high or low degree in the spatial regression modelling. In this process, a value of 1 in the inverse distance conceptualizations of spatial relationships was used to avoid computation of the default threshold and row standardization was applied.

\section{Results}

\section{Participants' characteristics}

A total of 6321 women aged 13-49 years living in the surveyed 5714 households were interviewed about their recent birth histories. Of these, 714 had a live birth in the last 12 months preceding the survey.

Caregivers of 3110 children under the age of 5 years living in the surveyed households were interviewed. Of these children, 2873 (92\%) were aged 2-59 months and 576 (16\%) were between 12 and 23 months.

The participating women were from Oromia (53\%), Amhara (24\%) Southern Nation, Nationality and People (13\%) and Tigray regions (10\%). More than half (53\%) of the women had no education while only $10 \%$ had completed secondary school or above. Forty percent of women who had a live birth during the last 12 months preceding the survey were orthodox Christian, followed by Muslims (30\%) and protestants (28\%).

\section{Maternal and child health care utilization}

Around one-third of the women with birth during the last year had attended antenatal care four or more times and almost half had delivered at a health facility (Table 2 and Fig. 2). The overall prevalence of reported common childhood illnesses (suspected pneumonia, diarrhoea or fever) in the 2 weeks prior to the survey was $139 / 2873$ (5\%; 95\% CI 3-7). Of these, $48 \%$ (95\% CI 40-57) sought care from a formal health provider (health post, health center, hospital or private clinic). The proportion of fully immunized children (12-23 months) was 41\% (95\% CI: 37-45).

\section{Spatial patterns in the utilization of maternal and child health care}

The presence of geographical clustering was analyzed for all selected outcome indicators using global spatial autocorrelation (Moran's' Index) as presented in Table 2. There were indications of geographic clustering in the utilization of facility delivery (Moran's $\mathrm{I}=0.205, p=$ 0.006 ) and full immunization coverage (Moran's I = $0.172, p=0.021$ ) (Table 2, Figs. 2 and 3). However, there

Table 2 Level of utilization and indications of geographic clustering of use of selected maternal and child health services in four national regions of Ethiopia, December 2016-February 2017

\begin{tabular}{|c|c|c|c|c|c|}
\hline Care utilization indicators & $\mathrm{n} / \mathrm{N}$ & $\%(95 \% \mathrm{Cl})$ & Moran's Index & Z-score of the Index & $P$-value \\
\hline \multicolumn{6}{|l|}{ Maternal health services } \\
\hline Four or more antenatal care visits & $215 / 714$ & $30(27-35)$ & 0.089 & 1.351 & 0.176 \\
\hline Delivery in a health facility & $336 / 714$ & $47(43-51)$ & 0.205 & 2.70 & 0.006 \\
\hline \multicolumn{6}{|l|}{ Child health services } \\
\hline Fully immunized children 12-23 months age & $232 / 567$ & $41(37-45)$ & 0.172 & 2.30 & 0.021 \\
\hline Utilization of care for common childhood illnesses during the last 2 weeks & $67 / 139$ & $48(40-57)$ & 0.016 & 0.454 & 0.640 \\
\hline
\end{tabular}



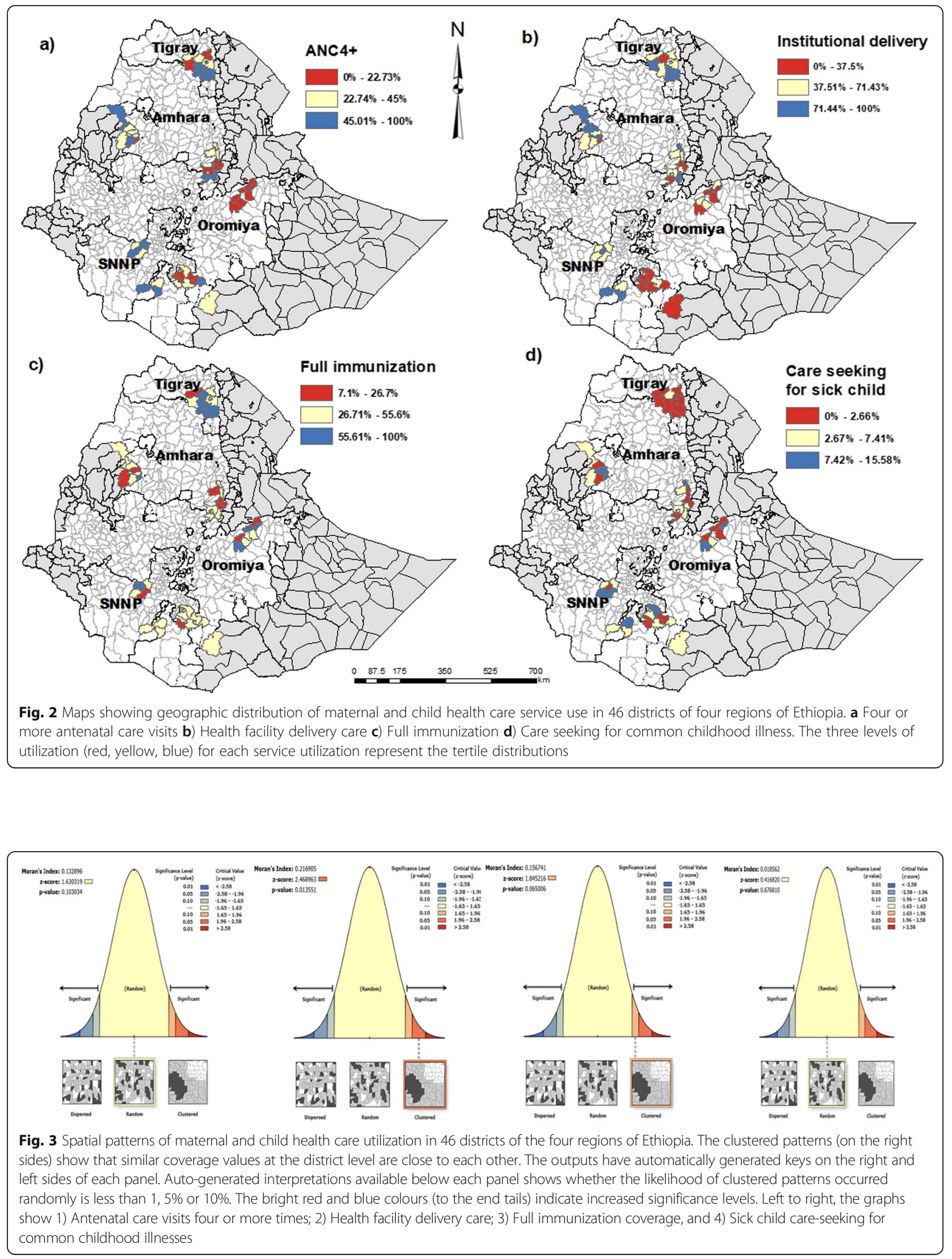
was neither indication of geographic clustering of four or more antenatal care visits nor of the utilization of health care when the under-five child was sick.

\section{Factors associated with maternal and child health care utilization}

The age and parity of women were associated with the utilization of antenatal care visits four or more times, while the number of antenatal care visits was associated with institutional delivery (Table 3). Caregivers' ownership of mobile phones was associated with full child immunization coverage, while none of the selected socio-demographic or health system characteristics was related to sick child care-seeking.

The distribution of standardized residuals from the Ordinary Least Squares models is shown in Fig. 4.

There was no evidence of spatial clustering of the residual in the OLS model for antenatal care four or more times, health facility delivery, or care-seeking of the sick child. The OLS model residual for full immunization

Table 3 Association between selected socio-geographic and health system factors and the geographical distribution of maternal and child health care utilization in 46 districts of Ethiopia, December 2016-February 2017

\begin{tabular}{|c|c|c|c|c|c|}
\hline Explanatory variables $^{a}$ & Estimate & Standard error & $t$-value & $p$ value & $\operatorname{Vif}^{\mathrm{b}}$ \\
\hline \multicolumn{6}{|l|}{ Antenatal care visits four times or more } \\
\hline Intercept & 0.283 & & & & \\
\hline Mean age of the women & 0.013 & 0.015 & 2.157 & $0.037^{* *}$ & 1.652 \\
\hline Mean education level of the women & -0.018 & 0.024 & -0.798 & 0.429 & 1.672 \\
\hline The proportion of households with a mobile phone & -0.002 & 0.000 & 0.911 & 0.368 & 1.606 \\
\hline Proportion of households with a radio & 0.000 & 0.000 & 1.083 & 0.285 & 1.799 \\
\hline Proportion of women's ownership of households & -0.002 & 0.004 & -0.544 & 0.589 & 1.157 \\
\hline Proportion of women having a family health card & 0.003 & 0.002 & 1.437 & 0.159 & 1.240 \\
\hline Mean parity & -0.111 & 0.039 & -2.882 & $0.006^{* *}$ & 1.724 \\
\hline \multicolumn{6}{|l|}{ Health facility delivery } \\
\hline Intercept & -0.195 & & & & \\
\hline Mean age of the women & 0.01 & 0.016 & 0.591 & 0.558 & 2.578 \\
\hline Mean number of pregnancies & -0.106 & 0.162 & -0.652 & 0.518 & 1.812 \\
\hline Mean number of antenatal care visits & 0.007 & 0.002 & 3.013 & $0.004^{* *}$ & 1.721 \\
\hline The proportion of women participating in women's development groups & 0.001 & 0.002 & 0.646 & 0.522 & 1.167 \\
\hline Proportion of women having a family health card & 0.003 & 0.002 & 1.484 & 0.145 & 1.196 \\
\hline Mean parity & -0.006 & 0.055 & -0.121 & 0.904 & 4.207 \\
\hline \multicolumn{6}{|l|}{ Full immunization } \\
\hline Intercept & 0.309 & & & & \\
\hline Mean distance to the health post & -0.001 & 0.001 & -0.91 & 0.368 & 1.406 \\
\hline Family size & -0.05 & 0.048 & -1.05 & 0.299 & 1.515 \\
\hline Mean radio availability in the household & -0.17 & 0.172 & -0.987 & 0.330 & 1.154 \\
\hline Mean mobile phone availability in the household & 0.206 & 0.109 & 1.896 & $0.046^{* *}$ & 1.274 \\
\hline Mean elevation & -0.000 & 0.000 & -0.65 & 0.519 & 1.273 \\
\hline Mean age of the child (in month) & 0.046 & 0.031 & 1.498 & 0.143 & 1.209 \\
\hline The proportion of male children & -0.195 & 0.225 & -0.867 & 0.392 & 1.705 \\
\hline Proportion of household with health post in their kebele & 0.179 & 0.229 & 0.785 & 0.437 & 1.265 \\
\hline \multicolumn{6}{|l|}{ Sick child care utilization } \\
\hline Intercept & -0.221 & & & & \\
\hline The proportion of household with health post in their kebele & 0.007 & 0.005 & 1.337 & 0.189 & 1.15 \\
\hline The proportion of male children & 0.004 & 0.008 & 0.530 & 0.599 & 1.153 \\
\hline Mean distance to health post (reported) & -0.004 & 0.004 & -1.212 & 0.232 & 1.055 \\
\hline
\end{tabular}

** Significance at $p$-value $<0.05$

${ }^{\mathrm{a}}$ The estimation was done at district level

bariance inflation factor 


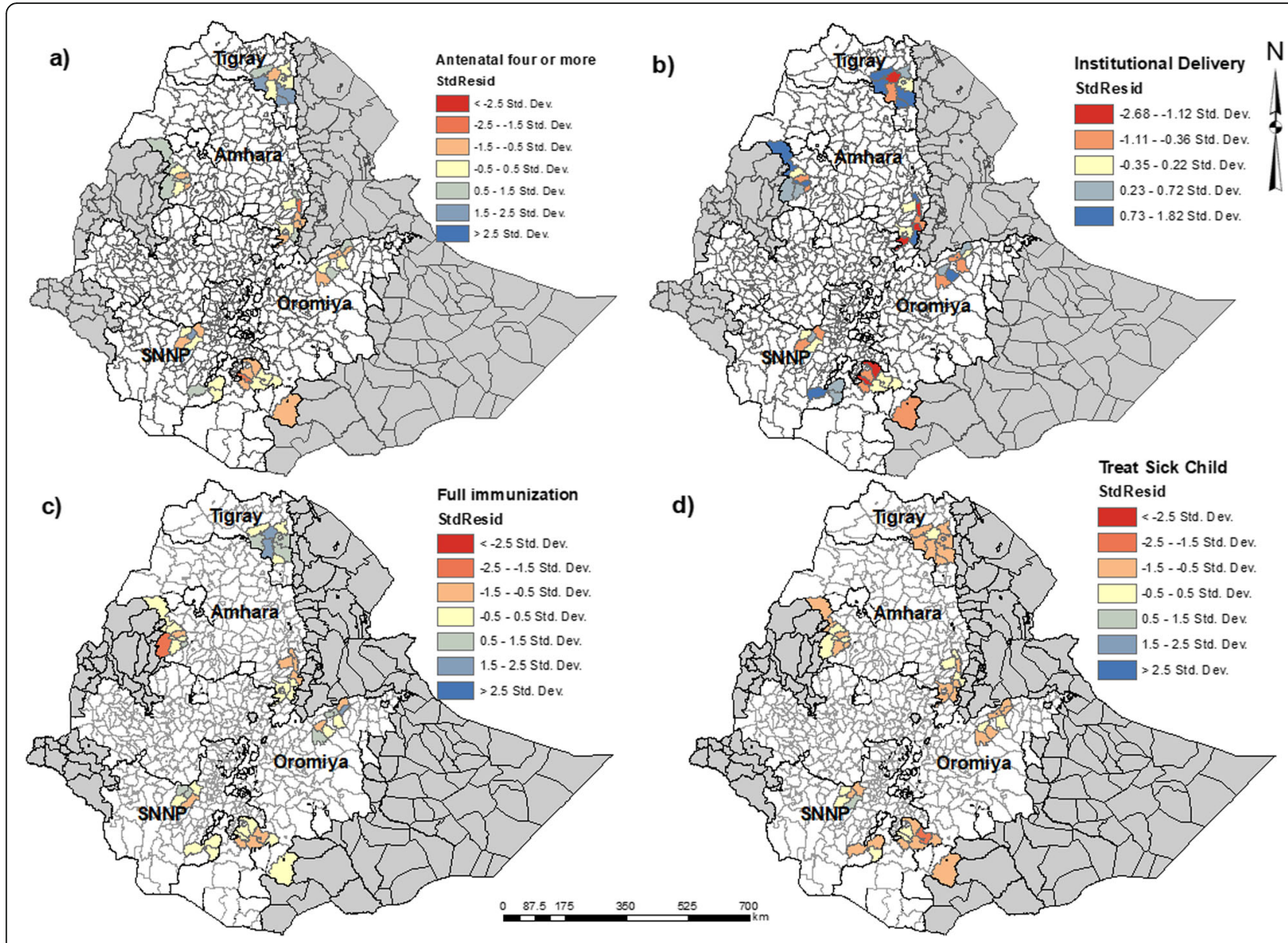

Fig. 4 Maps showing the distribution of the standard residuals from the OLS model a) Antenatal care visits four times or more b) Health facility delivery care c) Full immunization d) Sick child care-seeking for common childhood illnesses

coverage showed a significant spatial clustering (Moran's $\mathrm{I}=0.182$ and $p$-value $=0.032)($ Table 4$)$. Thus, we ran a Hot Spot Analysis using Getis Ord Gi*.

\section{Hot spot analysis}

As shown in Fig. 5, some of the districts in Tigray region showed indications of clustering of high levels of full immunization coverage that was not explained by the determinants included in the regression model. In contrast, in Oromia region there were districts with indications of clustered low coverage that was not explained by the included determinants. Other factors, not included in our models, might be associated with the geographical clustering of full immunization.

\section{Discussion}

We have shown that in the selected study districts of four Ethiopian regions there was geographical clustering in the utilization of facility-based delivery and in the coverage of full child immunization. The utilization of four or more antenatal care visits and care-seeking for

Table 4 Analysis of geographic clustering of residuals in the linear regression analyses of determinants of selected maternal and child health care utilization. Moran's I test statistics

\begin{tabular}{lllll}
\hline Outcome indicators & Morans' Index & Z-score of the Index & $p$-value & Interpretation \\
\hline Antenatal care visits four times or more & 0.025 & 0.488 & 0.625 & OLS residual was not clustered \\
Health facility delivery & 0.423 & 0.800 & 0.423 & OLS residual was not clustered \\
Immunization & 0.182 & 2.136 & 0.032 & OLS residual was clustered \\
Sick child care utilization & -0.052 & -0.039 & 0.752 & OLS residual was not clustered \\
\hline
\end{tabular}




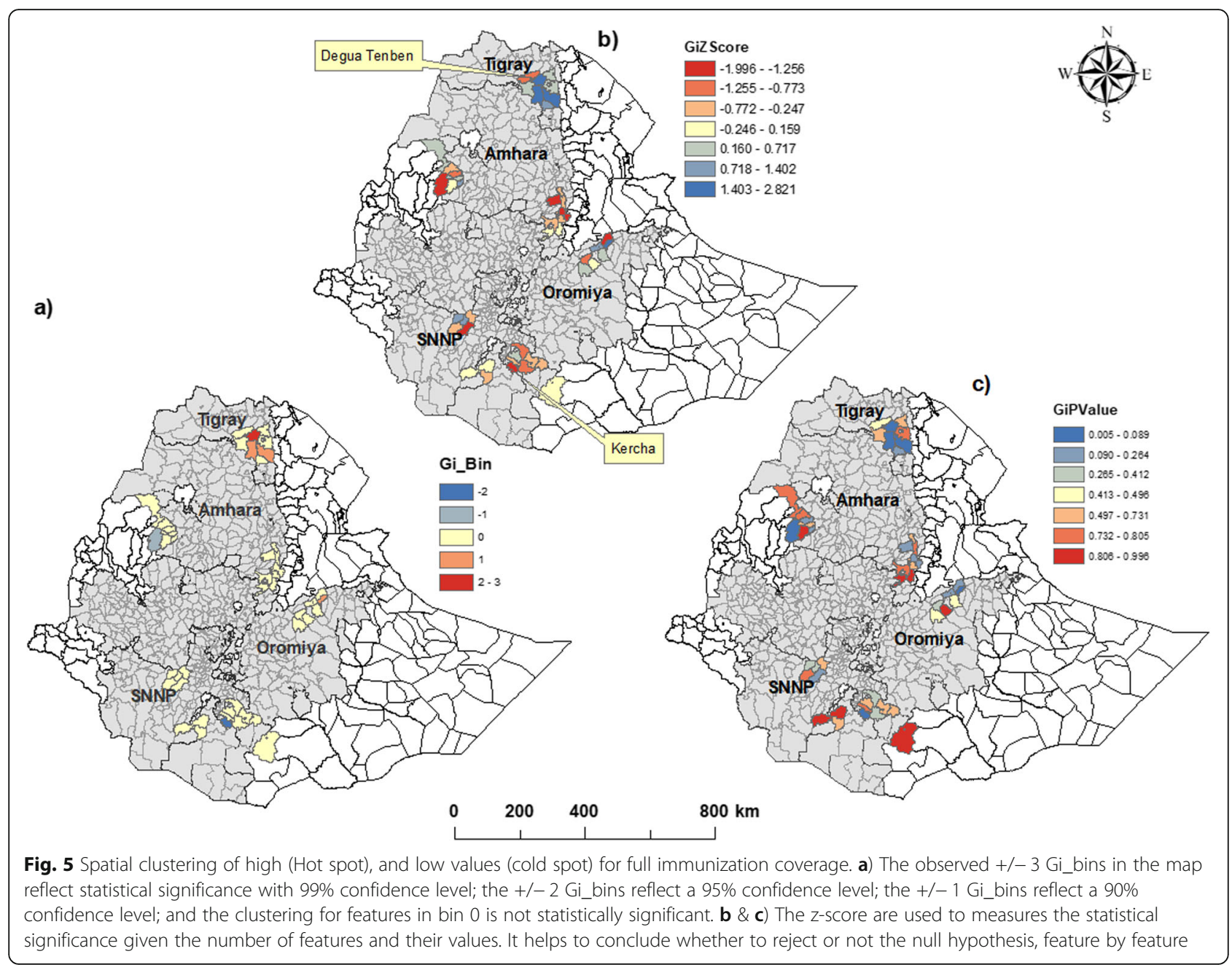

sick children were, however, randomly distributed in the study districts.

Previous analyses of three consecutive Ethiopian Demographic and Health Surveys showed a regional variation in the attendance to antenatal care [22]. Our study considered use of antenatal care related to births within 12 months prior to the study and applied spatial analysis, whereas the analyses of the Demographic Health Surveys reflected earlier 5-year periods and used conventional statistics to describe the geographical variation.

This study, as well as previous researches, have shown that mothers' age and parity were positively related to four or more antenatal care visits [23, 24]. Possible reasons for this finding may include that older and higher parity women have experiences that make them more aware of the potential benefits from antenatal care.

Antenatal care may be considered as a motivation for facility-based delivery care [25]. The clustering of facility delivery was associated with the number of antenatal care visits, which is in line with previous studies in Ethiopia [23, 26].

Full immunization coverage was clustered at district level, which indicates that similar levels of immunization coverage (higher or lower) were found in close geographical areas. A study conducted across different African countries found regional level clustering of low or high immunization coverage of measles, pentavalent, and BCG vaccines [27].

When analyzing potential factors that may affect clustering, we could only demonstrate an association between household ownership of a mobile phone and full immunization coverage. Characteristics such as distance to the health post or availability of a health facility in the village were not associated with full immunization. In contrast, researches from other countries have reported that clustering of vaccination was associated with location and distance to health facilities [28-30]. In Ethiopia, however, immunization is to a large extent provided through outreach activities performed by the health 
extension workers that could explain this difference in findings. The statistical analysis of residuals revealed, however, that we were not able to satisfactorily identify determinants of clustering of full immunization at district level.

In this study, there was no geographical variation in careseeking for common childhood illnesses and none of the selected sociodemographic and health facility characteristics was found to be associated with care-seeking for the sick child. Other studies have, however, found that availability of health facility in the village, distance to the nearest health facility, and other socio-demographic characteristics to be associated with the geographical variation of care-seeking for the sick child [31, 32].

The current study has strengths and limitations. We selected a range of key maternal and child health services to study the geographical distribution of health service utilization at district level. In addition, we used advanced spatial analysis techniques to identify clustering of care utilization and to identify associated factors. The geographical location of the districts and the relatively small number of data points in our analysis may affect the spatial modelling and we were not able to conduct geographically weighted regression to analyze local-level variation due to the limited number of data points. Instead, we performed ordinary least square analysis to identify associations between individual, socio-demographic, and health services characteristics and care utilization outcomes. The number of sick under-five children was small, which limited the ability to identify geographical clustering of care utilization in the study areas. Other Ethiopian studies have reported geographical clustering of care-seeking for common childhood illnesses as well as geographical clustering of childhood morbidity [33, 34], which also have been found in other sub-Saharan African countries [7, 35, 36].

\section{Conclusion}

This study shed light on the geographical variation in utilization of health facility delivery care and child immunization across four Ethiopian regions [37]. Our finding showed a geographical variability in the use of some maternal and child health services at districts level, suggesting that there are area-specific factors that influence the utilization and coverage of these services. Identifying district-level factors that influence these outcomes may inform efforts to achieve geographical equitability and universal coverage of maternal and child health services in Ethiopia.

\section{Abbreviations}

ANC: Antenatal Care; AOR: Adjusted Odds Ratio; CoC: Continuum of Care; COR: Crude Odds Ratio; CSV: Comma Separated values; EDHS: Ethiopian Demographic and Health Survey; EPHI: Ethiopian Public Health Institute; GWR: Geographically Weighted Regression; HF: Health Facility; HH: Household; LSHTM: London School of Hygiene and Tropical Medicine; MNC: Maternal-newborn and Child; MNCH: Maternal-newborn and Child;
PNC: Postnatal Care; SA: Spatial Autocorrelation; SA: Spatial Autocorrelation; SERO: Scientific Ethical Review Office

\section{Acknowledgements}

The authors would like to thank all stakeholders who contributed to the survey. We also thank the representatives of the regional health bureaus and district health offices for their smooth and kind cooperation. Special thanks to all field staff, who supported the data collection.

\section{Authors' contributions}

All authors contributed to proposal development and write-up of the research. AD analyzed and interpreted the data and drafted the manuscript with contributions from $K A, Y O$, and LÅP. All authors assisted in data interpretation, critical review of the manuscript and approved the final version of the manuscript.

\section{Funding}

This research was funded by the Bill and Melinda Gates Foundation through a grant to the London School of Hygiene \& Tropical Medicine (OPP1132551).

\section{Availability of data and materials}

The datasets analyzed in the current study available at the data repository centre of the EPHI. The corresponding author may be contacted for data request.

\section{Ethics approval and consent to participate}

Informed consent was obtained from all study participants. Ethical approval was obtained from the Ethiopian Public Health Institute (SERO-012-8-2016; Version 001), and research permit was obtained from the Regional Health Bureaus in Amhara, Oromia, SNNP, and Tigray. Ethical approval was also obtained from the London School of Hygiene \& Tropical Medicine (LSHTM Ethics Ref: 11235), while approval for the mapping component was acquired from the University of Gondar research ethics board. Children with overt medical problem were advised to get service in a nearby health facility. In addition, the field staff provided support in getting such care. Assent and consent from the parents were optioned for the women less than 18 years.

Consent for publication

Not applicable.

\section{Competing interests}

The authors declare that they have no competing interests.

\section{Author details}

${ }^{1}$ Ethiopian Public Health Institute, Addis Ababa, Ethiopia. ${ }^{2}$ Department of Epidemiology and Biostatistics, Institute of Public Health, College of Medicine and Health Sciences, University of Gondar, Gondar, Ethiopia. ${ }^{3}$ London School of Hygiene \& Tropical Medicine, London, UK. ${ }^{4}$ Department of Paediatrics and Child Health, School of Medicine and Health Science, University of Gondar, Gondar, Ethiopia.

Received: 13 September 2019 Accepted: 22 October 2019

Published online: 12 November 2019

\section{References}

1. Ruducha J, Mann C, Singh NS, Gemebo TD, Tessema NS, Baschieri A, et al. How Ethiopia achieved millennium development goal 4 through multisectoral interventions: a countdown to 2015 case study. Lancet Global Health. 2017;5(11):1142-51 http://www.sciencedirect.com/science/article/pii/ S2214109X17303315.

2. Yourkavitch J, Burgert-brucker C, Assaf S, Delgado S. Using geographical analysis to identify child health inequality in sub-Saharan Africa. PLoS One. 2018;13(Mdg 4):1-23.

3. Brownwright TK, Dodson ZM, Van Panhuis WG. Spatial clustering of measles vaccination coverage among children in sub-Saharan Africa. BMC Public Health. 2017;17(957):1-7.

4. Sisay MM, Geremew TT, Demlie YW, Alem AT, Beyene DK, Melak MF, et al. Spatial patterns and determinants of postnatal care use in Ethiopia: findings from the 2016 demographic and health survey. BMJ Open. 2019;9(6): e025066. https://doi.org/10.1136/bmjopen-2018-025066. 
5. Yeneneh A, Alemu K, Dadi AF, Alamirrew A. Spatial distribution of antenatal care utilization and associated factors in Ethiopia: evidence from Ethiopian demographic health surveys. BMC Pregnancy Childbirth. 2018;18(1):1-12.

6. Amsalu ET, Akalu TY, Gelaye KA. Spatial distribution and determinants of acute respiratory infection among under-five children in Ethiopia: Ethiopian demographic health survey 2016. PLoS One. 2019;14(4):1-14.

7. Bogale GG, Gelaye KA, Degefie DT, Gelaw YA. Spatial patterns of childhood diarrhoea in Ethiopia : data from Ethiopian demographic and health surveys (2000, 2005, and 2011). BMC Infect Dis. 2017;17:1-10.

8. Utazi CE, Thorley J, Alegana VA, Ferrari MJ, Takahashi S, Metcalf CJE, et al. Mapping vaccination coverage to explore the effects of delivery mechanisms and inform vaccination strategies. Nat Commun. 2019;10(1):110. https://doi.org/10.1038/s41467-019-09611-1.

9. Okwaraji YB, Mulholland K, Schellenberg J, Andarge G, Admassu M, Edmond $\mathrm{KM}$. The association between travel time to health facilities and childhood vaccine coverage in rural Ethiopia. A community-based cross-sectional study. BMC Public Health. 2012;12(1):1.

10. Okwaraji $Y B$, Webb EL, Edmond KM. Barriers in physical access to maternal health services in rural Ethiopia. BMC Health Serv Res. 2015:1-8. https://doi.org/10.1186/s12913-015-1161-0.

11. Ayele DZ, Belayihun B, Teji K, Ayana DA. Factors affecting utilization of maternal health Care Services in Kombolcha District, eastern Hararghe zone, Oromia regional state, eastern Ethiopia. Int Sch Res Not. 2014;2014(2001):17. https://doi.org/10.1155/2014/917058 Hindawi Publishing Corp.

12. Ebener S, Guerra-Arias M, Campbell J, Tatem AJ, Moran AC, Amoako Johnson F, et al. The geography of maternal and newborn health: the state of the art. Int J Health Geogr. 2015;14(1):19 http://www.ij-healthgeographics. com/content/14/1/19.

13. Matthews Z, Rawlins B, Duong J, Molla YB, Moran AC, Singh K, et al. Geospatial analysis for reproductive, maternal, newborn, child and adolescent health : gaps and opportunities. BMJ Glob Health. 2019;4:1-5.

14. Jin C, Cheng J, Lu Y, Huang Z, Cao F. Spatial inequity in access to healthcare facilities at a county level in a developing country: a case study of Deqing County, Zhejiang, China. Int J Equity Health. 2015;14(1):1-21. https://doi.org/10.1186/s12939-015-0195-6.

15. Makanga PT, Schuurman N, Sacoor C, Boene HE, Vilanculo F, Vidler M, et al. Seasonal variation in geographical access to maternal health services in regions of southern Mozambique. Int J Health Geogr. 2017;16(1):1-16.

16. Nesbitt RC, Gabrysch S, Laub A, Soremekun S, Manu A, Kirkwood BR, et al. Methods to measure potential spatial access to delivery care in low- and middle-income countries : a case study in rural Ghana. Int J Health Geogr. 2014:13(25):4-13.

17. Makanga PT, Schuurman N, Von Dadelszen P, Firoz T. A scoping review of geographic information systems in maternal health. Int J Gynecol Obstet. 2016;134(1):13-7. https://doi.org/10.1016/j.ijgo.2015.11.022.

18. Leong YY, Yue JC. A modification to geographically weighted regression. Int J Health Geogr. 2017;16:1-18.

19. Shaw NT, Mcguire SK. Understanding the use of geographical information systems (GISs) in health informatics research: a review. J Innov Heal Inform. 2017;24(2):228-33.

20. Csa. Population Census Commission ii. Mortality. 2007;385 Available from: http://www.csa.gov.et/surveys/Population and Housing census/ETH-pop2007/survey0/data/Doc/Reports/National_Statistical.pdf.

21. Wei W, Yuan-yuan J, Ci Y, Ahan A, Ming-qin C. Local spatial variations analysis of smear-positive tuberculosis in Xinjiang using geographically weighted regression model. BMC Public Health. 2016:1-9. https://doi.org/10.1186/s12889-016-3723-4

22. Yesuf EA, Calderon-Margalit R. Disparities in the use of antenatal care service in Ethiopia over a period of fifteen years. BMC Pregnancy Childbirth. 2013;13(1):1.

23. Wilunda C, Quaglio G, Putoto G, Takahashi R, Calia F, Abebe D, et al. Determinants of utilisation of antenatal care and skilled birth attendant at delivery in south west Shoa zone, Ethiopia: a cross-sectional study. Reprod Health. 2015;12(1):1-12. https://doi.org/10.1186/s12978-015-0067-y.

24. Tarekegn SM, Lieberman LS, Giedraitis V. Determinants of maternal health service utilization in Ethiopia: analysis of the 2011 Ethiopian demographic and health survey. BMC Pregnancy Childbirth. 2014;14(1):1-13.

25. Birmeta K, Dibaba Y, Woldeyohannes D. Determinants of maternal health care utilization in Holeta town, Central Ethiopia. BMC Health Serv Res. 2013;13(1):1
26. Kidanu S, Degu G, Tiruye TY. Factors influencing institutional delivery service utilization in Dembecha district, Northwest Ethiopia: a community-based cross-sectional study. Reprod Health. 2017;14(1):1-8.

27. Mosser JF, Gagne-maynard W, Rao PC, Osgood-zimmerman A, Fullman N, Graetz N, et al. Mapping diphtheria-pertussis-tetanus vaccine coverage in Africa, 2000-2016 : a spatial and temporal modelling study. Lancet. 2020; 393(10183):1843-55. https://doi.org/10.1016/S0140-6736(19)30226-0.

28. Blanford Jl, Kumar S, Luo W, MacEachren AM. It's a long, long walk: accessibility to hospitals, maternity and integrated health centers in Niger. Int J Health Geogr. 2012;11:1-15.

29. Tanser F, Gijsbertsen B, Herbst K. Modelling and understanding primary health care accessibility and utilization in rural South Africa: an exploration using a geographical information system. Soc Sci Med. 2006;63(3):691-705.

30. Al-Taiar A, Clark A, Longenecker JC, Whitty CJM. Physical accessibility and utilization of health services in Yemen. Int J Health Geogr. 2010;9:1-8.

31. Taffa N, Chepngeno G. Determinants of health care seeking for childhood illnesses in Nairobi slums. Trop Med Int Health. 2005:10(3):240-5.

32. Awoyemi TT, Obayelu OA, Opaluwa HI. Effect of distance on utilization of health Care Services in Rural Kogi State, Nigeria. J Hum Ecol. 2011;35(1):1-9.

33. Azage M, Kumie A, Alemayehu Worku ACB. Childhood diarrhea exhibits spatiotemporal variation in Northwest Ethiopia: a SaTScan spatial statistical analysis. PLoS One. 2016;10(12):1-18.

34. Munoz UH, Kallestal C. Geographical accessibility and spatial coverage modelling of the primary health care network in the Western Province of Rwanda. Int J Health Geogr. 2012;11(1):1-11 http://www.ij-healthgeographics. com/content/11/1/40

35. Osei FB, Stein A. Spatial variation and hot-spots of district-level diarrhoea incidences in Ghana: 2010-2014. BMC Public Health. 2017;17(617):1-10.

36. Adekanmbi VT, Adedokun ST, Taylor-phillips S, Uthman OA, Clarke A. Predictors of differences in health services utilization for children in Nigerian communities. Prev Med (Baltim). 2017;96:67-72. https://doi.org/10.1016/j.ypmed.2016.12.035.

37. Kerber KJ, de Graft-Johnson JE, Bhutta ZA, Okong P, Starrs A, Lawn JE. Continuum of care for maternal, newborn, and child health: from slogan to service delivery. Lancet. 2007;370(9595):1358-69.

\section{Publisher's Note}

Springer Nature remains neutral with regard to jurisdictional claims in published maps and institutional affiliations.

Ready to submit your research? Choose BMC and benefit from:

- fast, convenient online submission

- thorough peer review by experienced researchers in your field

- rapid publication on acceptance

- support for research data, including large and complex data types

- gold Open Access which fosters wider collaboration and increased citations

- maximum visibility for your research: over $100 \mathrm{M}$ website views per year

At $\mathrm{BMC}$, research is always in progress.

Learn more biomedcentral.com/submission 